\title{
Para uma crítica da medicalização na educação
}

\author{
Marisa Eugênia Melillo Meira
}

\section{Resumo}

Este artigo analisa criticamente o processo crescente de medicalização da vida cotidiana e suas expressões contemporâneas no campo da educação escolar à luz dos pressupostos da Psicologia Histórico-Cultural, buscando desvelar o processo de produção dos fenômenos do não aprender e não se comportar na escola, bem como os fatores que determinam sua identificação por profissionais da saúde e da educação como sintomas de doenças e transtornos. Dentre as muitas disfunções comumente associadas ao desempenho escolar de crianças na atualidade, são destacados e analisados o TDAH e o TOD. As análises desenvolvidas ao longo do texto indicam que a compreensão da medicalização como um desdobramento inevitável do processo de patologização dos problemas educacionais exige um trabalho intelectual crítico e o desenvolvimento de novos posicionamentos de psicólogos, educadores e profissionais da saúde em relação à sociedade, à educação e ao desenvolvimento humano. Palavras-chave: Medicalização, problemas de aprendizagem, Psicologia Histórico-Cultural.

\section{For a critique of medicalization in education}

\begin{abstract}
In this article we analyze the growing process of medicalization in everyday life and its contemporary expressions in the field of school education under the light of the assumptions of Historical-Cultural Psychology. We aim at unveiling the production process of the phenomena of non learning and misbehavior at school as well as the factors that determine their identification by health professionals and education as symptoms of diseases and disorders. Among the many disorders commonly associated with school performance of children today, are highlighted and analyzed ADHD and ODD. The analyzes carried out throughout the text indicate that the understanding of medicalization as an inevitable unfolding of the pathological process of educational problems requires a critical intellectual work and the development of new opinions of psychologists, educators and health professionals in relation to society, education and human development.
\end{abstract}

Keywords: Medicalization, learning disabilities, Historic-Cultural Psychology.

\section{Para una crítica de la medicalización en la educación}

\section{Resumen}

Este artículo analiza críticamente el proceso creciente de medicalización de la vida cotidiana y sus expresiones contemporáneas en el campo de la educación escolar a la luz de los supuestos de la Psicología Histórico-Cultural. Busca desvelar el proceso de producción de los fenómenos de no aprender y no comportarse bien en la escuela, así como los factores que determinan su identificación como síntomas de enfermedades y trastornos por profesionales de salud y de educación. Entre muchas disfunciones comúnmente asociadas al rendimiento escolar de niños en la actualidad son destacados y analizados el TDAH y el TOD. Los análisis desarrollados a lo largo del texto indican que la comprensión de la medicalización como un despliegue inevitable del proceso de patologización de los problemas educacionales exige un trabajo intelectual crítico y el desenvolvimiento de nuevos posicionamientos de psicólogos, educadores y profesionales de la salud en relación a la sociedad, a la educación y al desarrollo humano.

Palabras Clave: Medicalización, problemas de aprendizaje, Psicología Histórico-Cultural. 


\section{Introdução}

\section{Para uma crítica da medicalização na educação}

Este artigo analisa criticamente o processo crescente de medicalização da vida cotidiana e suas expressões contemporâneas no campo da educação escolar à luz dos pressupostos da Psicologia Histórico-Cultural. Em consonância com Moysés (2001), entendemos por medicalização o processo por meio do qual são deslocados para o campo médico problemas que fazem parte do cotidiano dos indivíduos. Desse modo, fenômenos de origem social e política são convertidos em questões biológicas, próprias de cada indivíduo.

Para Welch, Schwartz e Woloshin (2008), a medicalização da vida cotidiana, capaz de transformar sensações físicas ou psicológicas normais (tais como insônia e tristeza) em sintomas de doenças (como distúrbios do sono e depressão), vem provocando uma verdadeira "epidemia" de diagnósticos. Os progressos tecnológicos, os quais permitem a produção de equipamentos e testes capazes de fazer diagnósticos de indivíduos que ainda não apresentam sintomas de doenças, aliados a alterações contínuas dos valores de referência utilizados para se diagnosticar doenças ${ }^{1}$, têm como consequência principal a transformação de grandes contingentes de pessoas em pacientes potenciais.

Os autores advertem ainda que essa "epidemia" de diagnósticos produz na mesma escala uma "epidemia" de tratamentos, muitos dos quais altamente prejudiciais à saúde, especialmente nos casos em que não seriam de fato necessários. Tal situação é altamente vantajosa para a indústria farmacêutica, que vem cada vez mais ocupando lugar central na economia capitalista. Os grandes laboratórios vêm mostrando grande capacidade e eficiência na utilização de concepções equivocadas sobre doença e doença mental, amplamente enraizadas no senso comum, o que lhes permite alimentar continuamente o "sonho" de resolução de todos os problemas por meio do controle psicofarmacológico dos comportamentos humanos.

Não se trata obviamente de criticar a medicação de doenças, nem de negar as bases biológicas do comportamento humano. O que se defende é uma firme contraposição em relação às tentativas de se transformar problemas de viver em sintomas de doenças ou de se explicar a subjetividade humana pela via estrita dos aspectos orgânicos.

Concordamos com Costa (1994) no sentido de que as descobertas científicas no campo da genética e da psicofarmacologia precisam ser compreendidas em suas necessárias articulações com o contexto histórico concreto. Nas palavras do autor:

A psicofarmacologia pode muito bem descobrir as drogas

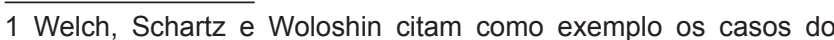
diabetes, hipertensão e colesterol, cujos valores de referência caíram tanto que atualmente mais da metade da população americana poderia ser considerada doente. que diminuam a "depressão" dos indivíduos; a genética pode determinar qual a origem cromossômica de cada suspiro, grito ou gemido que venhamos a dar, mas o que nenhuma das duas pode fazer é criar um sujeito moralmente responsável pelo que faz, diz ou sofre, se insistir em desconhecer ou não discutir as razões de nossos feitos, discursos ou sofrimentos (Costa, 1994, p.13)

Nessa mesma direção, Moysés (2001) defende a necessidade de rompermos com a esfera estreita da perspectiva individualizante que sustenta as visões biologizantes, como condição para entrarmos no campo da reflexão crítica sobre valores, fundamental para a compreensão do próprio significado de saúde e doença em suas múltiplas determinações.

Tomando como fundamento os pressupostos da Psicologia Histórico-Cultural, compreendemos que a dimensão biológica é a primeira condição para que um indivíduo se coloque como um "candidato" à humanidade. Entretanto, a humanização só pode se concretizar quando, em contato com o mundo objetivo e humanizado, transformado pela atividade real de outras gerações e por meio da relação com outros homens, o homem aprende a ser homem (Leontiev, 1978a).

É o processo de apropriação da experiência acumulada pelo gênero humano no decurso da história social, possível apenas na relação com outros homens, que permite a aquisição das qualidades, capacidades e características humanas e a criação contínua de novas aptidões e funções. De modo diferente dos animais, o homem garante suas aquisições, não se adaptando ao mundo dos objetos humanos, mas sim se apropriando deles. A apropriação é "um processo por meio do qual se produz na criança o que nos animais se consegue mediante a hereditariedade: a transmissão para o indivíduo das conquistas da espécie" (Leontiev, 1978a, p.105).

O social não apenas "interage" com o biológico, ele é capaz de criar novos sistemas funcionais que engendram novas formas superiores de atividade consciente. Como indica Vigotski (1995), é preciso compreender o desenvolvimento humano como um processo vivo, de permanente contradição entre o natural e o histórico, o orgânico e o social.

É a partir dessa perspectiva que vamos analisar as expressões contemporâneas da medicalização no campo da educação.

\section{A medicalização na educação}

O discurso da conexão entre problemas neurológicos e o não aprender ou não se comportar de forma considerada adequada pela escola apresenta-se de forma cada vez mais frequente no cotidiano das escolas e dos serviços públicos e particulares de saúde para os quais se encaminham grandes contingentes de alunos com queixas escolares. Nessa perspectiva se considera que crianças apresentam dificuldades escolares por causa de disfunções ou transtornos neu- 
rológicos (congênitas ou provocadas por lesões ou agentes químicos), as quais interferem em campos considerados pré-requisitos para a aprendizagem, tais como: percepção e processamento de informações; utilização de estratégias cognitivas; habilidade motora; atenção; linguagem; raciocínio matemático; habilidades sociais etc.

Cecília Azevedo Lima Collares e Maria Aparecida Affonso Moysés vêm apontando em seus estudos várias expressões desse processo de biologização. Pesquisas realizadas pelas autoras (Collares \& Moysés, 1994, 1996) evidenciam que tanto profissionais da saúde quanto da educação referem-se de modo unânime a problemas biológicos como causas determinantes do não aprender na escola. Tais "explicações", repetidas à exaustão e frequentemente evocadas como verdades científicas consagradas, colocam predominantemente o foco em dois grandes temas: a desnutrição e as disfunções neurológicas.

No que tange ao primeiro tema, Collares e Moysés dedicaram-se, em várias obras ${ }^{2}$, ao desvelamento dos mitos que estabelecem relações causais entre a desnutrição e as dificuldades de escolarização. As autoras afirmam que crianças que frequentam a rede pública de ensino, comumente rotuladas como desnutridas, são na verdade portadoras de desnutrição leve, de $1^{\circ}$ grau, ${ }^{3}$ que não trazem nenhum tipo de alteração para o sistema nervoso central. Além disso, as funções neurológicas que poderiam ser afetadas pela desnutrição nem sequer estariam presentes por volta de sete anos, não podendo, portanto, serem admitidas como explicações plausíveis para o não aprender.

Tratemos agora do tema das disfunções neurológicas, muito mais nebuloso e complexo que o anterior. Dentre as muitas disfunções comumente associadas ao desempenho escolar de crianças, destacaremos os mais referidos por profissionais da saúde e educação na atualidade: Transtorno de Déficit de Atenção e Hiperatividade (TDAH) e o Transtorno de Oposição e Desafio (TOD).

Iniciamos com a análise da definição, dos critérios diagnósticos e do tratamento indicado para o TDAH.

\section{O Transtorno de Déficit de Atenção e Hiperatividade (TDAH)}

Como indicam Eidt e Tuleski (2007a), já no final do século XIX há registros de pesquisas sobre crianças agressivas com dificuldades de controlar seus impulsos. Mas, apenas a partir da década de 1970, o interesse dos pesquisadores pelo TDHA aumenta. Na década de 1990 ele se transforma em um dos principais motivos de encaminhamento para tratamento médico e psicológico.

2 Para maior aprofundamento do tema, indicamos a leitura dos textos "Desnutrição e fracasso escolar: uma relação tão simples?" (1982); "A história não contada dos distúrbios de aprendizagem" (1992) e "Preconceitos no cotidiano escolar: ensino e medicalização" (1996).

3 Collares e Moysés (1996) sustentam que a desnutrição só pode comprometer o desenvolvimento se for grave (de $3^{\circ} \mathrm{grau}$ ) e ocorrer no início da vida e perdurar por um período de tempo longo.
Vejamos a definição de TDAH e algumas considerações gerais sobre sintomas, apresentadas no Manual de Diagnóstico e Estatística das Perturbações Mentais - IV Edição (DSM-IV) da Associação Americana de Psiquiatria4:

A característica essencial do TDAH é um padrão persistente de desatenção e/ou hiperatividade, mais frequente e severo do que aquele tipicamente observado em indivíduos em nível equivalente de desenvolvimento. [...] Os indivíduos com esse transtorno podem não prestar muita atenção a detalhes ou podem cometer erros por falta de cuidados nos trabalhos escolares ou outras tarefas. O trabalho frequentemente é confuso e realizado sem meticulosidade nem consideração adequada. Os indivíduos com frequência têm dificuldade para manter a atenção em tarefas ou atividades lúdicas e consideram difícil persistir em tarefas até seu término. Eles frequentemente dão a impressão de estarem com a mente em outro local, ou de não escutarem o que recém foi dito. [...] Esses indivíduos com frequência têm dificuldades para organizar tarefas e atividades. As tarefas que exigem um esforço mental constante são vivenciadas como desagradáveis e acentuadamente aversivas. [...] Os indivíduos com este transtorno são facilmente distraídos por estímulos irrelevantes e habitualmente interrompem tarefas em andamento para dar atenção a ruídos ou eventos triviais. [...] A hiperatividade pode manifestar-se por inquietação ou remexer-se na cadeira, por não permanecer sentado quando deveria, por correr ou subir excessivamente em coisas quando isto é inapropriado, por dificuldade em brincar ou ficar em silêncio em atividade de lazer, por frequentemente estar "a todo vapor" ou "cheio de gás" ou por falar em excesso. [...] Os indivíduos com este transtorno tipicamente fazem comentários inoportunos, interrompem demais os outros, metem-se em assuntos alheios, agarram objetos de outros, pegam coisas que não deveriam tocar e fazem palhaçadas. A impulsividade pode levar a acidentes e ao envolvimento em atividades potencialmente perigosas, sem consideração quanto às possíveis consequências.

No site da Associação Brasileira de Déficit de Atenção $(A B D A)^{5}$ o TDAH é definido como um transtorno neurobiológico de causas genéticas que aparece na infância e frequentemente acompanha o indivíduo por toda a sua vida. Nesse mesmo site é apresentado um questionário denominado SNAP-IV 6 , cujo objetivo é auxiliar a identificação de possíveis sintomas do TDAH em alunos e no qual constam as seguintes afirmações: "não consegue prestar muita atenção a detalhes ou comete erros por descuido nos trabalhos da escola ou tarefas; tem dificuldade de manter a atenção em tarefas ou atividades de lazer; parece não estar ouvindo quando se fala diretamente com ele; não segue instruções

4 O Manual de Diagnóstico e Estatística das Perturbações Mentais é uma publicação da Associação Americana de Psiquiatria, sendo a sua $4^{a}$ edição conhecida pela designação DSM-IV.

5 http://www.tdah.org.br/ , acesso em 15 ago. 2010.

6 Segundo informações do site, esse questionário foi construído considerando-se os sintomas apresentados no DSM-IV. 
até o fim e não termina deveres de escola, tarefas ou obrigações; tem dificuldade para organizar tarefas e atividades; evita, não gosta ou se envolve contra a vontade em tarefas que exigem esforço mental prolongado; perde coisas necessárias para atividades (p. ex: brinquedos, deveres da escola, lápis ou livros); distrai-se com estímulos externos; é esquecido em atividades do dia a dia; mexe com as mãos ou os pés ou se remexe na cadeira; sai do lugar na sala de aula ou em outras situações em que se espera que fique sentado; corre de um lado para outro ou sobe demais nas coisas em situações em que isto é inapropriado; tem dificuldade em brincar ou envolver-se em atividades de lazer de forma calma; não para ou frequentemente está a "mil por hora"; fala em excesso; responde às perguntas de forma precipitada antes de elas terem sido terminadas; tem dificuldade de esperar sua vez; interrompe os outros ou se intromete (p.ex. mete-se nas conversas/jogos)". Após ler cada uma dessas afirmações, o professor deve escolher a opção que considera mais adequada dentre as seguintes: nem um pouco, só um pouco, bastante e demais.

Após a escolha das opções, as respostas são avaliadas. Casos nos quais pelo menos seis itens sejam marcados como "BASTANTE" ou "DEMAIS", nas afirmações de 1 a 9, serão considerados indicativos de que existem mais sintomas de desatenção que o esperado em uma criança ou adolescente. Naqueles casos nos quais existam pelo menos seis itens marcados como "BASTANTE" ou "DEMAIS", nas afirmações de 10 a 18, isso será considerado indicativo de que existem mais sintomas de hiperatividade e impulsividade que o esperado em uma criança ou adolescente.

Tanto a descrição do transtorno quanto o tipo de sintomas que sustentam o seu diagnóstico revelam a falta de uma análise crítica sobre as relações entre os fenômenos que ocorrem na educação e o contexto histórico-social que a determina. Sem essa reflexão, o resultado é inevitável: muitas crianças absolutamente normais podem iniciar uma "carreira" de portadores de dificuldades de aprendizagem.

A consequência lógica desse olhar patologizante é a indicação de tratamento das crianças com TDAH o mais cedo possível. Grevet, Salgado, Zeni, \& Belmonte-de-Deus (2007, p. 37), por exemplo, defendem que o tratamento seja "vigoroso e precoce", uma vez que consideram que o transtorno provoca alterações na conduta que se mantêm na vida adulta, inclusive aumentando as chances de envolvimento com atividades criminosas, já na adolescência.

Na grande maioria dos casos, o tratamento envolve a administração de um medicamento denominado ritalina. Trata-se do metilfenidato, do grupo das anfetaminas, que atua como um estimulante do sistema nervoso central, potencializando a ação de duas substâncias cerebrais: a noradrenalina e a dopamina. Atualmente existe no mercado uma nova apresentação do metilfenidato denominada concerta.

$\mathrm{Na}$ bula da ritalina ${ }^{7}$, bastante extensa, constam várias informações importantes, entre as quais destacamos: "o medicamento pode provocar muitas reações adversas; seu

7 A bula pode ser consultada no site www.bulas.med.br. mecanismo de ação no homem ainda não foi completamente elucidado e o mecanismo pelo qual o multifenidato exerce seus efeitos psíquicos e comportamentais em crianças não está claramente estabelecido, nem há evidência conclusiva que demonstre como esses efeitos se relacionam com a condição do sistema nervoso central; a etiologia específica dessa síndrome é desconhecida e não há teste diagnóstico específico; o diagnóstico correto requer a investigação médica, neuropsicológica, educacional e social; pode causar dependência física ou psíquica" (grifos nossos).

Apesar da clara e assumida complexidade do diagnóstico, da imprecisão na própria definição do transtorno, do desconhecimento sobre todos os fatores envolvidos na ação do medicamento sobre o sistema nervoso central e das advertências feitas pelo próprio fabricante sobre reações adversas e riscos de dependência, o consumo do medicamento aumenta em velocidade crescente. De acordo com o Instituto Brasileiro de Defesa dos usuários de Medicamentos - IDUM, nos últimos anos o consumo do metilfenidato aumentou em 1616\%. Em 2000 foram vendidas 71 mil caixas e em 2008 esse número chegou a 1.147 .000 (um milhão e cento e quarenta e sete mil) caixas ${ }^{8}$.

Além do evidente caráter ideológico da configuração dada ao transtorno, ainda chama a atenção a total inconsistência no tratamento teórico dos fenômenos envolvidos. Embora se coloque o foco na atenção e na hiperatividade, tais conceitos são apresentados como dados em si, sem nenhuma reflexão sobre seu significado.

Do ponto de vista da Psicologia Histórico-Cultural, a atenção depende do desenvolvimento da capacidade humana de selecionar os estímulos e do controle voluntário do comportamento, sem os quais não seria possível aos homens desenvolver uma atividade coordenada com vistas a alcançar fins determinados (Luria, 1991).

O caráter social do desenvolvimento da atenção foi amplamente analisado por Vigotski. Para o autor, o indivíduo, no decorrer de sua vida, elabora uma série de signos artificiais que the permitem conhecer os estímulos que o afetam, dominar seus processos de comportamento e, portanto, assumir o controle do que faz, sente e pensa (Vigotski, 1995).

A atenção é uma função psicológica que deve ser constituída ao longo de processos educativos na infância e cujo desenvolvimento depende da qualidade dos mediadores culturais oferecidos pelos adultos (Eidt \& Tuleski, 2007b). Desse modo, não se trata de esperar que as crianças naturalmente sejam atentas na escola, independente dos conteúdos, da qualidade do trabalho pedagógico e das necessidades e possibilidades do desenvolvimento infantil. É preciso que os professores auxiliem cada criança a desenvolver cada vez mais a consciência e o controle sobre seu próprio comportamento de tal forma que ela possa propor-se, de modo intencional e deliberado, a focalizar sua atenção no processo de apropriação dos conteúdos escolares.

É um verdadeiro contrassenso que a escola exija da criança funções psicológicas superiores em relação às

8 Esses dados estão disponíveis no site www.idum.org.br. 
quais deveria assumir um papel diretivo e efetivo. A lógica biologizante tem levado pessoas a se perguntarem "o que a criança tem que não consegue prestar atenção?”. É preciso formular outro tipo de pergunta: o que na escola produz a falta de atenção e concentração? Essa mesma problematização deve ser feita em relação à hiperatividade.

A primeira questão a ser esclarecida é que não é possível falar de fato em aprendizagem se não houver um aluno que participe ativamente do processo educativo. $O$ pensamento educacional crítico já evidenciou, de modo suficiente, a impossibilidade de simplesmente se "depositar" o saber na "cabeça" dos alunos nos moldes da "educação bancária”, denunciada por Paulo Freire. Entretanto, a contraposição à pedagogia tradicional aqui defendida nada tem a ver com as ideias escolanovistas, constitutivas do ideário construtivista que, para superestimarem a participação dos alunos, acabam por negar a importância da transmissão do conhecimento feita pelo professor, valorizando apenas as aprendizagens que aqueles fazem sozinhos, de acordo com seus interesses imediatos ${ }^{9}$.

À luz da Psicologia Histórico-Cultural, compreendemos que a atividade é uma categoria central, já que todo o desenvolvimento psicológico do homem é estruturado a partir da atividade humana. Em consonância com o marxismo, os homens se formam no processo de trabalho no qual produzem os meios necessários para a satisfação de suas necessidades biológicas e também daquelas mais complexas, geradas nas relações sociais. Por meio do trabalho se objetivam nos produtos que constroem, transferindo para os objetos (materiais ou não) sua atividade física e mental. Nesse processo de objetivação, os homens criam e transformam continuamente a cultura humana.

O conceito de atividade tal como foi desenvolvido, especialmente por Leontiev (1978a, 1978b), traz inúmeras repercussões para a reflexão crítica sobre as práticas educativas. Por ora, vamos nos deter apenas em uma questão que nos interessa mais diretamente nesse momento: o aluno deve manter-se ativo no processo educativo fundamentalmente porque essa é uma condição indispensável à apropriação dos conteúdos escolares. Como destaca Mello (2003), cabe ao professor dirigir intencionalmente o processo educativo, mas este só terá sentido se as crianças puderem participar dentro dos limites e possibilidades de sua condição de alunos.

Esclarecida a importância e o sentido da atividade dos alunos para o desenvolvimento de propostas educacionais qualitativamente superiores, cabe indagarmos o que seria a hiperatividade. Qual seria o limite existente entre um aluno que participa ativamente e um aluno considerado hiperativo? De quais fenômenos estamos tratando? Doenças ou desvios da norma? Transtornos ou não adaptação à ordem estabelecida?

Concordamos com Eidt (2004) no sentido de que há muitas semelhanças nas descrições comportamentais de

\footnotetext{
9 Para aprofundar essa questão, indicamos a leitura da obra "Aprender a aprender: crítica às apropriações neoliberais e pósmodernas da teoria vigotskiana", de Newton Duarte (2000).
}

crianças e adolescentes com diagnóstico de TDAH e daqueles considerados indisciplinados. Vejamos a listagem dos comportamentos indisciplinados mais apontados pelos professores em relação a seus alunos: conversam muito, são agitados, não ficam sentados, falam palavrões, são agressivos/violentos (brigam, ofendem ou agridem fisicamente colegas, professores e funcionários), respondem afrontosamente ao professor, não se concentram nas atividades, exibem roupas ou comportamentos considerados indecentes, fumam ou usam álcool e drogas na escola e destroem ou danificam materiais próprios e dos colegas ou, ainda, o patrimônio da escola.

Qual seria efetivamente a diferença entre esses comportamentos e os sintomas de TDAH anteriormente descritos? Em uma visão tradicional, o sentido da disciplina é o da obediência e, dependendo das escolas e dos professores, um mesmo comportamento pode ou não ser considerado indisciplinado. Ou, ainda, pode ser visto como sintoma de TDAH.

Novamente nos deparamos, por um lado, com o tema da normatização das condutas e, por outro, com a mesma atitude passiva de professores que esperam que, ao entrar na escola, os alunos rompam de maneira imediata com as formas de comportamento cotidianas, adaptem-se de modo completo às regras e normas institucionais e apresentem-se "naturalmente" disciplinados e silenciados.

É evidente que não se pode realizar nenhum trabaIho pedagógico sem disciplina. Entretanto, ela é importante apenas quando construída cotidianamente com a finalidade de se colocar a serviço da função social da escola: socializar conhecimentos e desenvolver pensamento crítico.

E se pudéssemos romper com esse olhar que patologiza o sujeito indisciplinado que se encontra na origem dos diagnósticos de TDAH e mudássemos o foco, buscando compreender como diferentes contextos e práticas produzem a indisciplina? Talvez então fosse possível trazer para o centro desse debate situações de miséria social que produzem sentimentos de desesperança; a disseminação de modelos violentos e "hiperativos" em todos os espaços sociais; o desinteresse pelos problemas coletivos e a exacerbação do individualismo; a degradação das escolas públicas; a inadequação das propostas pedagógicas; a desvalorização dos professores; os relacionamentos sociais opressivos e desumanizadores ...

Mas, infelizmente, estamos caminhando cada vez mais em direção ao recrudescimento da patologização.

\section{O Transtorno Desafiante de Oposição (TOD)}

Segundo Grevet e cols. (2007), perto de $70 \%$ dos pacientes com TDAH apresentam maior prevalência de comorbidades do que pessoas sem o transtorno. Dentre os transtornos associados, destaca-se o transtorno desafiante de oposição (TOD), que, segundo os autores, pode ser diag- 
nosticado em até $60 \%$ das crianças e $40 \%$ dos adultos com $\mathrm{TDAH}^{10}$

No DSM-IV ${ }^{11}$ encontramos a seguinte definição desse transtorno:

A característica essencial do TOD é um padrão recorrente de comportamento negativista, desafiador, desobediente e hostil para com figuras de autoridade, que persiste por pelo menos seis meses. [...] os comportamentos negativistas ou desafiadores são expressados [sic] por teimosia persistente, resistência a ordens e relutância em comprometer-se, ceder ou negociar com adultos ou seus pares. O desafio também pode incluir testagem deliberada ou persistente dos limites, geralmente ignorando ordens, discutindo e deixando de aceitar a responsabilidade pelas más ações. A hostilidade pode ser dirigida a adultos ou a seus pares, sendo demonstrada ao incomodar deliberadamente ou agredir verbalmente outras pessoas.

Para Serra-Pinheiro, Schmitz e Mattos (2004, p. 273), trata-se de um transtorno disruptivo que leva os indivíduos a "perderem facilmente o controle se as coisas não seguem a forma que eles desejam".

Para se chegar ao diagnóstico do transtorno desafiante de oposição, o DSM-IV recomenda que se observe a existência de pelo menos quatro sintomas entre os que seguem: "encoleriza-se frequentemente; discute com adultos ou figuras de autoridade; costuma desafiar as regras dos adultos; faz coisas deliberadamente para aborrecer a terceiros; culpa os outros pelos seus próprios erros; sente-se ofendido com facilidade; tem respostas coléricas quando contrariado; é rancoroso e vingativo quando desafiado ou contrariado" (grifos nossos). Apesar de recomendarem alguns cuidados ${ }^{12}$ na definição do diagnóstico de TOD, Grevet e cols. (2007) não analisam os próprios conceitos que fundamentam o diagnóstico: desafio e oposição.

Questões vitais não são respondidas, até porque nem sequer são formuladas. A que tipo de ordem se desobedece? Qual o conteúdo da oposição? Que regras são desafiadas? Por que o não cumprimento das regras tem que terminar necessariamente em discussão com os adultos? Que relações assimétricas de poder são essas entre adultos e crianças que apenas são capazes de produzir confronto e não diálogo? Os sentimentos de cólera não estariam sendo produzidos pela vivência continuada de situações de exclusão e preconceito? O que está sendo tratado como resis-

10 Os autores também analisam a associação de TDAH com transtorno de conduta (TC) e transtorno de personalidade antissocial (TPAS).

11 A consulta foi realizada no site http://www.psicologia.com.pt/ instrumentos/dsm cid/dsm.php. Acesso em 12 set. 2010.

12 Segundo os autores, os sintomas "devem se apresentar como um padrão persistente em múltiplos ambientes e estar presentes há pelo menos seis meses. Para se fazer o diagnóstico de TOD, o paciente não pode apresentar concomitantemente um transtorno psicótico ou um transtorno afetivo. Também, o paciente não pode preencher os critérios para transtorno de conduta (menores de 18 anos) ou personalidade anti-social (em maiores de 18 anos)" (Grevet e cols., 2007, p. 37). tência e confrontação patológica não seria a expressão de pensamento crítico sufocado e neutralizado pela ciência já no seu nascedouro? Que tipo de homem estamos formando? Para que sociedade?

Tudo indica que nessa perspectiva as relações humanas entre professores e alunos na escola são pensadas apenas a partir de vínculos de dependência, estes sim patológicos porque altamente produtores de frustração e alienação. A ausência de reciprocidade e respeito mútuo impede a efetivação de relações saudáveis e humanizadoras.

Estamos diante da total ausência de crítica! Estamos pedindo às crianças que prestem atenção em tudo o que Ihes é apresentado, mesmo que esses conteúdos não façam o menor sentido! E, ainda mais: que não se irritem com nada disso, mesmo que por vezes a situação lhes pareça insuportável!

\section{Finalizando}

\begin{abstract}
O tema da exclusão social nos põe diante de um conjunto grande de incertezas em relação à sociedade contemporânea e à nossa capacidade de sair do abismo que elas representam ... Mas, na angústia que o motiva, representa também a demanda de uma compreensão positiva e libertadora das causas e características dos problemas que a consciência social assinala, teme e questiona. O que pede, portanto, o trabalho intelectual crítico em relação à prática social e política fundada na estreiteza e nas deturpações dessa concepção limitada e limitante. E pede, também, às ciências sociais o desvendamento dos conteúdos do projeto potencial que encerra, coisas que o senso comum não tem tido condição de fazer". J. S. Martins (2002, p. 12-13)
\end{abstract}

A constatação e análise crítica do aumento crescente do processo de medicalização da educação, bem como a identificação de suas manifestações contemporâneas são fundamentais, porém ainda insuficientes. É preciso ir além e compreender a que demandas sociais ela vem atender, desvelando tanto o processo de produção dos fenômenos do não aprender e não se comportar na escola, quanto os fatores que determinam sua identificação por profissionais da saúde e da educação como sintomas de doenças e transtornos.

A medicalização constitui-se em um desdobramento inevitável do processo de patologização dos problemas educacionais que tem servido como justificativa para a manutenção da exclusão de grandes contingentes de crianças pobres que, embora permaneçam nas escolas por longos períodos de tempo, nunca chegam a se apropriar de fato dos conteúdos escolares.

Como destaca Bourdieu (1997), esse processo de "exclusão do interior" garante a manutenção da exclusão dos mais pobres e se apresenta como uma das formas contemporâneas importantes de produção da miséria social. Crianças e jovens das camadas populares continuam a ser eliminados. Entretanto, ocorre uma diferença fundamental: 
essa eliminação é adiada, já que se mantêm na escola os excluídos potenciais.

Para esses "marginalizados por dentro", a escola permanece como uma espécie de "terra prometida" ou uma miragem que se mantém sempre presente no horizonte, mas que recua à medida que tentam se aproximar dela.

Como explicar essa situação absolutamente evidente nas estatísticas educacionais? Qual seria a explicação para o fato de que os alunos permanecem na escola, mas não aprendem? A resposta que vem sendo dada de diferentes formas é clara: nem todas as crianças reuniriam as condições necessárias para aprender os conteúdos escolares. A escola é para todos, mas nem todos podem aproveitar essa oportunidade em decorrência de problemas individuais. Essa é a essência da patologização e o ponto de partida para a consolidação do processo de medicalização.

Em síntese, a escola não cumpre sua função social de socialização do saber e produz problemas que serão tratados como demandas para a saúde em diferentes espaços sociais (escolas, serviços públicos de saúde, saúde mental e assistência social, consultórios etc.).

A humanidade produziu inúmeras possibilidades de desenvolvimento, entretanto a grande maioria dos indivíduos encontra-se submetida a processos de empobrecimento material e espiritual. É nessa situação que se encontram as crianças e jovens cujas capacidades de desenvolvimento são aprisionadas nas redes da patologização que se tecem a muitas mãos no interior das escolas.

O impedimento de acesso das crianças pobres aos bens culturais é parte de um processo de ocultação da produção e reprodução das desigualdades sociais e, por isso, exige um trabalho intelectual crítico, capaz de realizar rupturas epistemológicas e desenvolver novos posicionamentos em relação à sociedade e à educação.

A Psicologia tem que se comprometer de fato com o rompimento com a patologização, tomando como objeto de ação e reflexão o encontro entre os alunos e a educação e contribuindo para que a escola cumpra seu papel social (Meira, 2003, 2007). Essa é uma tarefa que envolve uma atitude de permanente avaliação crítica da realidade e a articulação de elaborações teóricas que se constituam em indicativos para a organização consciente e deliberada de ações com vistas à garantia de condições que permitam o máximo desenvolvimento possível dos indivíduos.

\section{Referências}

American Psychiatric Association. (1994). Manual Diagnóstico e Estatístico de Transtornos Mentais (4a ed.). Washington, DC: Autor.

Bourdieu, P. (1997). A miséria do mundo (3a ed.). Rio de Janeiro: Editora Vozes.
Collares, C. L., \& Moysés, M. A. A. (1982). Desnutrição e fracasso escolar: uma relação tão simples? Revista da ANDE (5), 56-62.

Collares, C. L., \& Moysés, M. A. A. (1992). A história não contada dos distúrbios de aprendizagem. Caderno Cedes (28), 31-48.

Collares, C. L., \& Moysés, M. A. A. (1994). A transformação do espaço pedagógico em espaço clínico (A Patologização da Educação). Série Ideias (23), São Paulo, FDE, 25-31.

Collares, C. L., \& Moysés, M. A. A.(1996). Preconceitos no cotidiano escolar - ensino e medicalização. São Paulo: Cortez Editora.

Costa, J. F (1994). A utilidade do corpo inocente. Jornal Folha de São Paulo, São Paulo, 13 mar. Caderno Mais., p.13.

Duarte, N. (2000). Aprender a aprender: crítica às apropriações neoliberais e pós-modernas da teoria vigotskiana. Campinas, SP:Autores Associados.

Eidt, N. (2004). Transtorno do déficit de atenção e hiperatividade: diagnóstico ou rotulação? Dissertação de Mestrado, Pontifícia Universidade Católica de Campinas, Campinas-SP.

Eidt, N. M., \& Tuleski, S. C. (2007a). Discutindo a medicalização brutal em uma sociedade hiperativa. Em M. E. M. Meira \& M. G. D. Facci (Orgs.), Psicologia Histórico-Cultural. Contribuições para o encontro entre subjetividade e a educação (pp. 221-248). São Paulo: Casa do Psicólogo.

Eidt, N. M., \& Tuleski, S. C. (2007b). Repensando os distúrbios de aprendizagem a partir da psicologia histórico-cultural. Psicologia em Estudo 12(3), 531-540.

Grevet, E. H., Salgado, C. A. I, Zeni, G., \& Belmonte-de-Abreu, P.(2007). Transtorno de oposição e desafio e transtorno de conduta: os desfechos no TDAH em adultos. Jornal Brasileiro de Psiquiatria, 56, supl 1, 34-38.

Leontiev, A.(1978a). O desenvolvimento do psiquismo (3a ed.). Lisboa: Livros Horizonte.

Leontiev, A. (1978b). Actividad, conciencia y personalidad. Buenos Aires: Ciencias del Hombre.

Luria, A. R.(1991). Curso de psicologia geral: Atenção e Memória (Vol. VIII). Rio de Janeiro: Civilização Brasileira.

Martins, J. S. (2002). A sociedade vista do abismo - novos estudos sobre exclusão, pobreza e classes sociais. Petrópolis, RJ: Editora Vozes.

Meira, M. E. M. (2003). Construindo uma concepção crítica de Psicologia Escolar: contribuições da Pedagogia Histórico-Crítica e da Psicologia Sócio-Histórica. Em M. E. M Meira \& M. A. M. Antunes (Orgs.), Psicologia Escolar: Teorias Críticas (pp. 13-78). São Paulo: Casa do Psicólogo. 
Meira, M. E. M. (2007). Psicologia Histórico-Cultural: Fundamentos, pressupostos e articulações com a Psicologia da Educação. Em M. E. M. Meira, \& M. G. D. Facci (Orgs.), Psicologia HistóricoCultural: contribuições para o encontro entre a subjetividade e a educação. São Paulo: Casa do Psicólogo.

Mello, S. A. (2003). Uma reflexão sobre o conceito de mediação no processo educativo. Teoria e Prática em Educação, 6(12), 29-48.

Moysés, M. A. A. (2001). A institucionalização invisível - crianças que não-aprendem-na-escola. Campinas, SP: FAPESP/ Mercado de Letras.
Serra-Pinheiro, M. A., Schmitz, M., Mattos, P. (2004). Transtorno desafiador de oposição: uma revisão de correlatos neurobiológicos e ambientais, comorbidades, tratamento e prognóstico. Revista Brasileira de Psiquiatria, 26(4), 273-276.

Vigotski, L. S.(1995). Obras Escogidas III. Madri: Visor.

Welch, G, Schwartz, L, Woloshin, S. (2008). O que está nos deixando doentes é uma epidemia de diagnósticos. Jornal do Cremesp, p. 12, fev. (texto publicado no The New York Times, em 02/01/2007; tradução de Daniel de Menezes Pereira).

Recebido em: 14/06/2011

\section{Sobre a autora}

Marisa Eugênia Melillo Meira (marisaem.meira@gmail.com)

Departamento de Psicologia da Faculdade de Ciências da UNESP, campus de Bauru, Doutora em Psicologia Escolar e do Desenvolvimento Humano. Endereço: Rua Rinaldo Franco de Camargo n 5-166, Condomínio Shangrilá, Bauru-SP, CEP 17054-645. 